Englishes in Practice 2015; 2(2): 39-48

DOI 10.1515/eip-2015-0002

\title{
Tomokazu Ishikawa
}

Centre for Global Englishes, University of Southampton, UK. Email: ti1g12@soton.ac.uk

\section{Academic rigour in criticising English as a Lingua Franca ${ }^{1}$}

During my PhD fieldwork in 2014, I met a few linguistics students who purported to disapprove of English as a Lingua Franca (ELF). However, their disapproval seemed directed against something else in the name of ELF. To be specific, they believed that ELF was an alternative model for the English classroom or a distinct, monolithic variety for non-native English speakers (NNESs). Intriguingly, these beliefs are similar to how ELF is misrepresented by some scholars who have never engaged in ELF research themselves. Recent examples are Park and Wee (2011), Swan (2012) and Sewell (2013). It should be stressed that contrary to these authors' claims, Jenkins et al. (2011) and Seidlhofer (2011), to name just a couple of examples, take a clear position that ELF refers to dynamic, pluralistic manifestations of linguistic resources in an international setting, and that ELF interaction can involve native English speakers (NESs). In addition, Mauranen (2012) introduces the notion of similect, instead of variety, to conceptualise the fluid, contingent similarities and differences of the English used as a lingua franca by those from the same firstlanguage (L1) background.

ELF scholars have made efforts to clarify the above-mentioned misbeliefs and other misunderstandings (e.g., Seidlhofer 2006; Jenkins 2007, 2012). Jenkins (2007), in particular, provides an extensive review of how ELF is misinterpreted, including a detailed analysis of Sobkowiak (2005/2008), Kuo (2006) and Prodromou (2006). Certainly, such efforts have helped inform those less familiar with ELF. However, while ELF has now become a widely recognised research field, the same, old misrepresentations still never cease. Looking back at just the last three months from the time of this article preparation, we find Park and Wee (2015 - February), O'Regan (2014 - December) and Canagarajah (2014 - December). It is quite

\footnotetext{
${ }^{1}$ This article is based on a presentation at the University's Centre for Global Englishes seminar in March 2015.
} 
shocking to have seen all the three come out within such a short space of time. This article examines those three publications in turn (i.e., Park and Wee 2015; O'Regan 2014; Canagarajah 2014), and Park and Wee (2015) is discussed together with Park and Wee (2011).

In February 2015, Park and Wee (2015) published English as a lingua franca: Lessons for language and mobility as a revised version of their previous paper (i.e., Park and Wee 2011, A practice-based critique of English as a Lingua Franca). According to Park and Wee $(2011,2015)$, "the ELF research project" aims to identify and propagate "the ELF core" as an alternative set of formal linguistic features against an English-as-a-Native-Language (ENL) model, while largely neglecting socio-cultural diversity. Based on this interpretation of "the ELF research project", they criticise 'ELF research' for its tendency "to view language as a fixed, static and clearly delineable object" (Park and Wee 2015: 56) without having sociopolitical sensitivity.

Park and Wee's $(2011,2015)$ "ELF research project" entirely fails to address the actual research field of ELF. First of all, while ELF research started with Jenkins (2000) identifying 'the Lingua Franca Core (LFC)', 'the LFC' should not be viewed as a set of alternative prescribed features. This is because the use of 'the LFC' depends on interlocutors to accommodate (e.g., Jenkins 2000, 2002). Simultaneously, it should be stressed that the concept of 'the LFC' has never been applied outside phonology (e.g., Jenkins et al. 2011; Cogo 2012). Second, ELF research has not concentrated independently on formal linguistic features, because from ELF perspectives, form and function are not a priori, but emerge and operate interdependently during communicative acts (e.g., Seidlhofer 2009; Cogo and Dewey 2012). This is demonstrated, for examples, in Ranta (2006), Pitzl et al. (2008) and Mauranen $(2009,2012)$. Third, ELF interaction occurs in and across all three Kachruvian circles as pointed out by Seidlhofer (2004), the literature cited in Park and Wee $(2011,2015)$ several times. Accordingly, ELF research does not exclude NESs (e.g., Sweeney and Zhu 2010), but reflects the fact that international communication often does not include NESs (e.g., Jenkins 2009, 2015). And last, while it is true that Seidlhofer (2004) refers to the 'let-it-pass' principle (Firth 1996) as commonly found in precursor studies on ELF pragmatics, Park and Wee (2015: 65) should not have regarded it as "broad assertion" across ELF research - even as ELF researchers' excuse not to pay serious attention to socio-cultural diversity. This is because later research has revealed that ELF interaction is "heavily contentoriented" (Jenkins et al. 2011: 293) and socio-culturally rich (e.g., Baker 2009, in press; Cogo and Dewey 2012), employing diverse communication strategies (e.g., Mauranen 2006, 2012; Kaur 2009a, 2011; Björkman 2011, 2014) and often also plurilingual resources (e.g., Klimpfinger 2007, 2009; Hülmbauer 2009, 2011). 
Derived from the false premise of "the ELF research project", Park and Wee's (2011, 2015) criticism of 'ELF' "as [a] bounded, asocial entity" (Park and Wee 2015: $65)$ is completely off the mark. In actuality, ELF research "seeks to show how English is always under negotiation" (Pennycook 2009: 195), involving people from diverse socio-linguacultural backgrounds (e.g., Jenkins et al. 2011; Seidlhofer 2011; Mauranen 2012). Simultaneously, ELF scholars have explicitly dealt with sociopolitical issues, such as identity and ideology (e.g., Jenkins 2007; Seidlhofer 2011), power (e.g., Guido 2012; Hülmbauer 2013), policy (e.g., Jenkins 2014; Jenkins and Wingate in press), community (e.g., Seidlhofer 2007; Ehrenreich 2009) and culture (e.g., Baker 2009, in press).

In summary, Park and Wee's $(2011,2015)$ portrayal of ELF research is inaccurate and without regard to current ELF literature, despite the focus on ELF as shown in the titles of Park and Wee $(2011,2015)$. This being the case, they fail to provide a constructive argument. It might possibly be that their research interest does not include ELF, but that they choose this developing field to make their ideas noticed widely. After all, ELF continues attracting an increasing amount of research in diverse areas, as prominently seen in the Journal of English as a Lingua Franca, the book series, Developments in English as a Lingua Franca, and an annual ELF international conference series (see Jenkins 2015: 41).

In December 2014, O'Regan (2014) published English as a lingua franca: An immanent critique. ${ }^{2}$ According to him, "the ELF movement" constitutes the fetishism of an illusory, reified ELF variety, or a hypostatised "thing-in-itself" called ELF. In his understanding, "the ELF movement" appears insensitive to socio-linguacultural diversity, although he does not focus on language itself and its socio-cultural relationships. Based on this interpretation of "the ELF movement", he criticises 'ELF research' for reifying and hypostatising language without giving sufficient consideration to Marxian (1976) political economy or the "necessary" sociopolitical, philosophical conceptions of "ideology, discourse, power, truth and the nature of the real - and, particularly, the relations between them" (O'Regan 2014: 544).

O'Regan's (2014) "ELF movement" is his own illusion. ELF is the term referring to a dynamic, situational natural linguistic phenomenon which embraces diverse socio-linguacultural identities (e.g., Jenkins et al. 2011; Seidlhofer 2011; Mauranen 2012). This amorphous nature of ELF is incompatible with O'Regan's (2014) "thingin-itself", although he interprets short phrases, such as Jenkins et al.'s (2011) "ELF settings" and "ELF speakers", as implying reification and hypostatisation through the nominalisation of ELF. In the same vein, O'Regan's (2014) criticism of 'ELF' as a reified, hypostatised entity is simply wrong. Actually, this is exactly what ELF

\footnotetext{
${ }^{2}$ For response articles to O'Regan (2014), see Widdowson (2015), Baker et al. (2015) and Baker and Jenkins (2015).
} 
scholars strongly oppose (e.g., Jenkins et al. 2011; Seidlhofer 2011; Mauranen 2012; Mortensen 2013; Baird et al. 2014). Apart from reification and hypostatisation, O'Regan (2014) has little to say about ELF, making only a cursory and superficial treatment of linguistic, or more broadly, socio-linguacultural aspects. In addition, he imposes not only Marxian (1976) political economy, to which no ELF researcher has ever subscribed, but also the "necessary" conceptions mentioned above, while taking no notice of sociopolitical, philosophical discussions in ELF research (e.g., Jenkins 2007, 2014; Seidlhofer 2011; Mauranen 2012; Baird et al. 2014). Simply put, O'Regan (2014) imposes his own theoretical frameworks, without regard to pertinent arguments in ELF research, on the analysis of his own interpretation of "the ELF movement". Such can never be "an immanent critique". To borrow Widdowson's (2015: 127) words, "[t]he irony of this article [(i.e., O'Regan 2014)] is that while dogmatically asserting a particular way of thinking, it makes a claim to be a rational critique".

It should be added that O'Regan (2014) continues more or less with Park and Wee's (2011) misapprehension of ELF, and follows Swan's (2012) and Sewell's (2013) 'tactic' to criticise ELF, although O'Regan (2014) refers to none of the three. More specifically, O'Regan's (2014) "ELF movement" and criticism of "an (sic) hypostatized universal code" (p. 539) are similar to Park and Wee's (2011) hypothesised "ELF research project" and groundless criticism of "a fixed system". Simultaneously, as with Swan (2012) and Sewell (2013), O'Regan (2014) exploits short extracts for 'evidence' of reification. Along with the phrases mentioned previously (i.e., "ELF settings", "ELF speakers"), O'Regan (2014: 538) quotes the following sentence from Jenkins (2014: 38): "it is the skill of converging appropriately that constitutes 'correctness' in ELF". Here, O'Regan (2014) simply claims that ELF is reified and hypostatised through nominalisation (i.e., "in ELF"). However, Jenkins (2014) actually argues, in line with Cogo and Dewey (2012), that from ELF perspectives, correctness does not reside in any particular linguistic features, but resides in accommodation to interactants from different sociolinguacultural backgrounds by making flexible, contingent use of "a situational resource pool" (Hülmbauer 2009: 325, quoted in Jenkins 2014: 38).

In summary, O'Regan's (2014) portrayal of ELF research is uninformed and his criticism is irrational. This being the case, he fails to present scholarly debate. It might possibly be that like Park and Wee (2011, 2015), O'Regan (2014) does not have much interest in ELF, but that he uses this vibrant field to generate considerable interest in his own literature. Indeed, his next publication on ELF is coming shortly (O'Regan in press), whether constructive this time or unconstructive again. 
In December 2014, Canagarajah (2014) published In search of a new paradigm for teaching English as an international language. According to his interpretation of ELF, "[i]n the early work of this school, it was posited that this was another variety, labeled lingua franca core (LFC), that multilingual students would switch to when they used English for contact purposes (see Seidlhofer, 2001)" (Canagarajah 2014: 769). While Seidlhofer (2001) and other ELF scholars used to hypothesise that it might be possible to identify an ELF 'variety', or more possibly, a range of L1influenced 'varieties', no ELF researcher has ever labelled this hypothetical 'variety' or 'varieties' as 'the LFC'. In the first place, 'the LFC' has nothing to do with codifying linguistic regularities (Jenkins 2000, 2002). Also, what Canagarajah (2014) does not clarify is that "[a]ttempts to delineate ELF as a variety of language are not part of contemporary ELF discourses" (Baker and Jenkins 2015: 193). Certainly, Canagarajah's (2014) interpretation of ELF as 'the LFC variety' is akin to Park and Wee's $(2011,2015)$ and O'Regan's (2014) interpretations. However, his discourse in search of a 'new' paradigm seems rather peculiar.

Canagarajah's (2014) main section is the one called Pedagogical practice, in which he concentrates on his own English writing teaching practices. He cites ELF literature only once: "scholars of ELF have mentioned that teaching and research on the role of international English in writing has suffered greatly (Jenkins, Kogo (sic), \& Dewey, 2011)" (Canagarajah 2014: 775). However, Jenkins et al. (2011) actually point out that 'written ELF' is a recent interest, and that written language is the area whose change is relatively slow. Incidentally, a team at the University of Helsinki has just completed the Corpus of Written English as a Lingua Franca in Academic Settings (WrELFA), adding important empirical data to ELF research (WrELFA 2015).

In another section called Defining English, along with the above-mentioned claim of 'the LFC variety', Canagarajah (2014) makes the following two arguments in relation to ELF, citing no ELF researchers but only Canagarajah (2013) and Pennycook (2010). First, on the one hand, Canagarajah (2014: 769) assumes ELF (and world Englishes) to be "well established, stable, and self-structured varieties" which "have their own bounded identities" and "share a single norm". On the other hand, he argues that multilinguals negotiate English in a situationally appropriate manner to help achieve intelligibility. The same kind of argument on the multilinguals has, however, already been made, to provide just a few examples, in Jenkins et al. (2011), Seidlhofer (2011) and Mauranen (2012), with the proviso that ELF interaction can involve monolingual NESs who can accommodate their English as necessary. Second, whereas assuming ELF (and world Englishes) to be grammarfocused, Canagarajah (2014: 769) argues that in "the new approach", communicative success depends on "not our grammatical proficiency, but [on] our adeptness in negotiating the diversity of grammars in each specific interaction". What Canagarajah (2014) does not tell us, however, is that ELF researchers have 
already made similar points. As just one example, Cogo and Dewey (2012: 137) argue that "[m]eaning does not reside in the linguistic forms themselves, but rather in the mutual negotiation involved in their selection and manipulation".

Seeing that Canagarajah (2014) incorporates relatively recent ELF literature in his treatment of negotiation strategies (i.e., Kaur 2009b; Pitzl 2010), he might have been aware of actual ELF research development. However, again, Canagarajah's (2014) aforementioned two arguments in the Defining English section cite only his own work (i.e., Canagarajah 2013) and Pennycook (2010). What is more, Pennycook (2010) might not lend any additional support for the two arguments, because this literature might be mentioned on the grounds that it touches on Canagarajah's (2007) orientation to English which is detailed in Canagarajah (2013). It should be added that while Canagarajah (2007) adopts the label lingua franca English (LFE) (Firth 1996), this label conveys a false impression of one bounded entity, appearing parallel, for example, with British English or Indian English (see Seidlhofer 2011: 7677).

In summary, Canagarajah (2014) does not give due consideration to current ELF literature when comparing and contrasting between 'ELF research' and his orientation to English. It might possibly be that he seeks to show considerable 'differences' between them, thereby presenting his own ideas as more original than they are, and achieving more impact for them. In so doing, however, he fails to discuss ELF research accurately.

Whether they have responded to the popular field of ELF in order to be noticed and published, to try to claim originality and impact for their own ideas, or to meet other needs, Park and Wee (2011, 2015), O'Regan (2014) and Canagarajah (2014) in their different ways all seem to demonstrate lack of academic rigour in their presentation of ELF research. Their misrepresentations as discussed in this article are deleterious, and risk misinforming those who are less familiar with ELF, including students, into thinking that ELF research is 'unreasonable'. Such is likely to put new talent off joining this vibrant, growing research field.

I would like to conclude this article with a couple of comments. First and foremost, those who research in the field of ELF, including myself, ought to caution ourselves against following Park and Wee's (2011, 2015), O'Regan's (2014) and Canagarajah's (2014) examples when criticising a research field - especially an entire one, as is apparently the case with O'Regan (2014). What my senior colleague at the Centre for Global Englishes said is much to the point: "I never disagree with a whole research field because there are few that are entirely rejectable (and I especially wouldn't reject one I haven't read extensively within and with whose researchers I have not closely engaged)" (Robert Baird, personal communication). Second, I sincerely hope that the above authors, and potentially others, will 
discontinue misrepresenting our research field of ELF, and instead begin to contribute it and thus enlighten us in more constructive ways.

\section{Acknowledgement}

I would like to thank Dr. Ying Wang for suggesting that I write this article. I would also like to thank the editor, Jill Doubleday, two anonymous reviewers, and my fellow PhD candidates, Claire Cavanagh, Ali Karakaş and Sonia Morán Panero, for their valuable comments and suggestions. 


\section{References}

Baird, Robert, Will Baker \& Mariko Kitazawa. 2014. The complexity of ELF. Journal of English as a Lingua Franca 3(1). 171-196.

Baker, Will. 2009. The cultures of English as a lingua franca. TESOL Quarterly 43(4). 567-592.

Baker, Will. in press. Culture and identity through English as a lingua franca: Rethinking concepts and goals in intercultural communication. Berlin: De Gruyter Mouton.

Baker, Will \& Jennifer Jenkins. 2015. Criticising ELF. Journal of English as a Lingua Franca 4(1). 191198.

Baker, Will, Jennifer Jenkins \& Robert Baird. 2015. ELF researchers take issue with 'English as a lingua franca: an immanent critique'. Applied Linguistics 36(1). 121-123.

Björkman, Beyza. 2011. Pragmatic strategies in English as an academic lingua franca: Ways of achieving communicative effectiveness? Journal of Pragmatics 43(4). 950-964.

Björkman, Beyza. 2014. An analysis of polyadic English as a lingua franca (ELF) speech: A communicative strategies framework. Journal of Pragmatics 66. 122-138.

Canagarajah, Suresh. 2007. Lingua franca English, multilingual communities, and language acquisition. Modern Language Journal 91(s1). 923-939.

Canagarajah, Suresh. 2013. Translingual practice: Global Englishes and cosmopolitan relations. London: Routledge.

Canagarajah, Suresh. 2014. In search of a new paradigm for teaching English as an international language. TESOL Journa/5(4). 767-785.

Cogo, Alessia. 2012. English as a Lingua Franca: Concepts, use, and implications. ELT Journa/66(1). 97-105.

Cogo, Alessia \& Martin Dewey. 2012. Analysing English as a lingua franca: A corpus-driven investigation. London: Continuum.

Ehrenreich, Susanne. 2009. English as a lingua franca in multinational corporations - Exploring business communities of practice. In Anna Mauranen \& Elina Ranta (eds.), English as a lingua franca: Studies and findings, 126-151. Newcastle upon Tyne: Cambridge Scholars Publishing.

Firth, Alan 1996. The discursive accomplishment of normality: On 'lingua franca' English and conversation analysis. Journal of Pragmatics 26(2). 237-259.

Guido, Maria Grazia. 2012. ELF authentication and accommodation strategies in crosscultural immigration encounters. Journal of English as a Lingua Franca 1(2). 219-240.

Hülmbauer, Cornelia. 2009. "We don't take the right way. We just take the way that we think you will understand" - The shifting relationship between correctness and effectiveness in ELF. In Anna Mauranen \& Elina Ranta (eds.), English as a lingua franca: Studies and findings, 323-347. Newcastle upon Tyne: Cambridge Scholars Publishing.

Hülmbauer, Cornelia. 2011. Old friends?: Cognates in ELF communication. In Alasdair Archibald, Alessia Cogo \& Jennifer Jenkins (eds.), Latest trends in ELF research, 139-161. Newcastle upon Tyne: Cambridge Scholars Publishing.

Hülmbauer, Cornelia. 2013. From within and without: The virtual and the plurilingual in ELF. Journal of English as a Lingua Franca 2(1). 47-73.

Jenkins, Jennifer. 2000. The phonology of English as an International Language. Oxford: Oxford University Press.

Jenkins, Jennifer. 2002. A sociolinguistically based, empirically researched pronunciation syllabus for English as an International Language. Applied Linguistics 23(1). 83-103.

Jenkins, Jennifer. 2007. English as a Lingua Franca: Attitude and identity. Oxford: Oxford University Press.

Jenkins, Jennifer. 2009. World Englishes: A resource book for students, 2nd edn. London: Routledge. 
Jenkins, Jennifer. 2012. English as a Lingua Franca from the classroom to the classroom. ELT Journal 66(4). 486-494.

Jenkins, Jennifer. 2014. English as a Lingua Franca in the international university: The politics of academic English language policy. London: Routledge.

Jenkins, Jennifer. 2015. Global Englishes: A resource book for students, 3rd edn. London: Routledge.

Jenkins, Jennifer, Alessia Cogo \& Martin Dewey. 2011. Review of developments in research into English as a lingua franca. Language Teaching 44(3). 281-315.

Jenkins, Jennifer \& Ursula Wingate. in press. Staff and students' perceptions of English language policies and practices in 'international' universities: A case study from the UK. Higher Education Review.

Kaur, Jagdish. 2009a. Pre-empting problems of understanding in English as a lingua franca. In Anna Mauranen \& Elina Ranta (eds.), English as a lingua franca: Studies and findings, 107-123. Newcastle upon Tyne: Cambridge Scholars Publishing.

Kaur, Jagdish. 2009b. English as a lingua franca: Co-constructing understanding. Saarbrücken: VDM Verlag.

Kaur, Jagdish. 2011. Raising explicitness through self-repair in English as a lingua franca. Journal of Pragmatics 43(11). 2704-2715.

Klimpfinger, Theresa. 2007. 'Mind you, sometimes you have to mix' - The role of code-switching in English as a lingua franca. VIEWS - VIenna English Working PaperS 16(2). 36-61.

Klimpfinger, Theresa. 2009. "She's mixing the two languages together" - Forms and functions of code-switching in English as a lingua franca. In Anna Mauranen \& Elina Ranta (eds.), English as a lingua franca: Studies and findings, 348-371. Newcastle upon Tyne: Cambridge Scholars Publishing.

Kuo, I-Chun (Vicky). 2006. Addressing the issue of teaching English as a lingua franca. ELT Journal 60(3). 213-221.

Marx, Karl. 1976. Capital: A critique of political economy, volume 1. Trans. Ben Fowkes. Harmondsworth: Penguin.

Mauranen, Anna. 2006. Signaling and preventing misunderstanding in English as lingua franca communication. International Journal of the Sociology of Language 177. 123-150.

Mauranen, Anna. 2009. Chunking in ELF: Expressions for managing interaction. Intercultural Pragmatics 6(2). 217-233.

Mauranen, Anna. 2012. Exploring ELF: Academic English shaped by non-native speakers. Cambridge: Cambridge University Press.

Mortensen, Janus. 2013. Notes on English used as a lingua franca as an object of study. Journal of English as a Lingua Franca 2(1). 25-46.

O'Regan, John P. 2014. English as a lingua franca: An immanent critique. Applied Linguistics 35(5). 533-552.

O'Regan, John P. in press. Intercultural communication and the possibility of English as a lingua franca. In Prue Holmes \& Fred Dervin (eds.), The cultural and intercultural dimensions of English as a lingua franca. Clevedon: Multilingual Matters.

Park, Joseph Sung-Yul \& Lionel Wee. 2011. A practice-based critique of English as a Lingua Franca. World Englishes 30(3). 360-374.

Park, Joseph Sung-Yul \& Lionel Wee. 2015. English as a lingua franca: Lessons for language and mobility. In Christopher Stroud \& Mastin Prinsloo (eds.), Language, literacy and diversity: Moving words, 55-71. London: Routledge.

Pennycook, Alastair. 2009. Plurilithic Englishes: Towards a 3D model. In Kumiko Murata \& Jennifer Jenkins (eds.), Global Englishes in Asian contexts: Current and future debates, 194-207. Basingstoke: Palgrave Macmillan. 
Pennycook, Alastair. 2010. Language as a local practice. London: Routledge.

Pitzl, Marie-Luise. 2010. English as a lingua franca in international business: Resolving miscommunication and reaching shared understanding. Saarbrücken: VDM Verlag.

Pitzl, Marie-Luise, Angelika Breiteneder \& Theresa Klimpfinger. 2008. A world of words: Processes of lexical innovation in VOICE. VIEWS - VIenna English Working PaperS 17(2). 21-46.

Prodromou, Luke. 2006. Defining the 'successful bilingual speaker' of English. In Rani Rubdy \& Mario Saraceni (eds.), English in the world: Global rules, global roles, 51-70. London: Continuum.

Ranta, Elina. 2006. The 'attractive' progressive - Why use the -ing form in English as a lingua franca? Nordic Journal of English Studies 5(2). 95-116.

Seidlhofer, Barbara. 2001. Closing a conceptual gap: The case for a description of English as a lingua franca. International Journal of Applied Linguistics 11(2). 133-158.

Seidlhofer, Barbara. 2004. Research perspectives on teaching English as a lingua franca. Annual Review of Applied Linguistics 24. 209-239.

Seidlhofer, Barbara. 2006. English as a Lingua Franca in the Expanding Circle: What it isn't. In Rani Rubdy \& Mario Saraceni (eds.), English in the world: Global rules, global roles, 40-50. London: Continuum.

Seidlhofer, Barbara. 2007. English as a lingua franca and communities of practice. In Sabine VolkBirke \& Julia Lippert (eds.), Anglistentag 2006 Halle Proceedings, 307-318. Trier: Wissenschaftlicher Verlag Trier.

Seidlhofer, Barbara. 2009. Common ground and different realities: World Englishes and English as a lingua franca. World Englishes 28(2). 236-245.

Seidlhofer, Barbara. 2011. Understanding English as a lingua franca. Oxford: Oxford University Press. Sewell, Andrew. 2013. English as a lingua franca: Ontology and ideology. ELT Journa/67(1). 3-10.

Sobkowiak, Włodzimierz. 2005/2008. Why not LFC? In Katarzyna Dziubalska-Kołaczyk \& Joanna Przedlacka (eds.), English pronunciation models: A changing scene, 131-149. Bern: Peter Lang.

Swan, Michael. 2012. ELF and EFL: Are they really different? Journal of English as a Lingua Franca 1(2). 379-389.

Sweeney, Emma \& Hua Zhu. 2010. Accommodating toward your audience: Do native speakers of English know how to accommodate their communication strategies toward nonnative speakers of English? Journal of Business Communication 47(4). 477-504.

Widdowson, Henry G. 2015. Contradiction and conviction. A reaction to O'Regan. Applied Linguistics 36(1). 124-127.

WrELFA. 2015. Written academic ELF (WrELFA). http://www.helsinki.fi/englanti/elfa/wrelfa.html (accessed 30 March 2015).

Tomokazu Ishikawa is a PhD candidate in Applied Linguistics at the University of Southampton, a member of the University's Centre for Global Englishes, and a former English teacher at Japanese institutions for university-entrance-exam preparation. He holds an MA in TESOL from Teachers College, Columbia University, and an LLB from Keio University. 